TECHNICAL NOTES AND MANUALS

\title{
Commitment Controls
}

\author{
Dimitar Radev and Pokar Khemani
}

Fiscal Affairs Department

I NTERNATIONAL MONETARY FUND 


\section{INTERNATIONAL MONETARY FUND}

Fiscal Affairs Department

\section{Commitment Controls}

Prepared by Dimitar Radev and Pokar Khemani

Authorized for distribution by Carlo Cottarelli

October 2009

DISCLAIMER: This Technical Guidance Note should not be reported as representing the views of the IMF. The views expressed in this Note are those of the authors and do not necessarily represent those of the IMF or IMF policy.

\begin{tabular}{|l|l|}
\hline JEL Classification Numbers: & H50, H61 \\
\hline Keywords: & $\begin{array}{l}\text { public financial management, expenditure control, commitment control, } \\
\text { fiscal discipline, payment arrears, cash planning and management }\end{array}$ \\
\hline Author's E-mail Address: & dradev@imf.org; pkhemani@imf.org \\
\hline
\end{tabular}




\title{
TECHNICAL NOTES AND MANUALS
}

\section{Commitment Controls}

\author{
Prepared by Dimitar Radev and Pokar Khemani
}

\section{This note ${ }^{1}$ addresses the following main issues:}

- What are the objectives of commitment controls?

- What are the preconditions for successful implementation of commitment controls?

- What are the main institutional forms and operational arrangements of commitment controls?

- What are the implications for the IMF's operational work and technical assistance?

The three major objectives of a public financial management system (PFM) are: (1) fiscal discipline (expenditure control); (2) allocation of resources consistent with policy priorities (strategic allocation of resources); and, (3) prudent management of the government's financial resources (economy, efficiency, and effectiveness). These three objectives-together with the need for transparency and accountability in fiscal relations-are complementary and interdependent, though in many developing countries fiscal discipline, in many ways, is of paramount importance, and any efforts at addressing the other two objectives come next.

Expenditure control is an essential element of fiscal discipline. For control purposes, the literature distinguishes four main phases of the expenditure cycle: (i) authorization or allocation of appropriations to spending agencies; (ii) commitment-incurring a future obligation to pay; (iii) verification - the acquisition and verification of goods and services; and (iv) payments. There are specific forms of control during the different stages of the budget execution process. The current paper focuses on expenditure control at the commitment stage.

The focus on commitment controls is justified on the grounds of their important role in developing an overall expenditure control framework, as well as controlling the accumulation of

\footnotetext{
${ }^{1}$ An earlier version of this note was previously issued as part of a series of technical notes on the IMF's Public Financial Managment Blog (http://blog-pfm.imf.org). This note has benefited from peer review by B. Olden, G. Ljungman and $\mathrm{H}$. van Eden, helpful comments from other FAD/IMF colleagues, including R. Allen, D. Bouley, I. Fainboim, M. Lazare, and M. Pessoa, as well as very valuable comments by M. Williams, IMF consultant.
} 
payment arrears. Arrears have been an issue in a significant number of Fund-supported programs. ${ }^{2}$ The arrears typically arise from a breakdown of normal financial controls and may undermine fiscal adjustment programs.

The rest of this paper considers the following issues:

- the definition and objectives of commitment controls;

- preconditions for successful implementation of commitment controls;

- institutional design of commitment controls; and

- implications for the IMF's operational work and technical assistance.

\section{Definition and Objectives of Commitment Controls}

\section{Definition}

Commitment means an obligation to make a future payment subject to the fulfillment of certain conditions (contractual or otherwise). There are two main types of commitments: (i) specific commitments; and (ii) continuing/running commitments.

Specific commitments are those that will require a single payment or a series of payments over a determinate period of time. These include contracts for goods and services, or any similar arrangement, and occur when a formal action is taken by a line ministry, such as placing an order for supply of goods and services, issuing a local purchase order, or awarding a contract to a supplier.

Continuing commitments are those that will require a series of payments or settlement actions over an indeterminate period of time, and might not involve a specific contract. These include wages, utilities, scholarships, entitlement payments, and other similar arrangements.

A standard approach to defining commitments by economic category of expenditure and cash requirements for payments is presented in Box 1 .

\section{Objectives}

The commitment of resources is a critical stage of the expenditure process. Controlling commitments is essential for controlling expenditure. The key objective of commitment control is to manage the initial incurrence of obligations, rather than the subsequent cash payments, in order to enforce expenditure ceilings and avoid expenditure arrears (see Box 2). To this end, the commitment control system imposes limits on commitments. These limits can be based on budget appropriations or on cash plans. Ideally, commitments should be regulated by annual budget appropriations. However, this approach may prove to be insufficient in preventing the

\footnotetext{
${ }^{2}$ Nearly one-half of all countries with programs in effect during 1993-99 had a performance criteria (PC) on arrears at some point during the period. Compliance with PCs on arrears has been lower than on the more traditional quantitative fiscal PCs.
} 


\section{Box 1. Commitment and Cash Requirements for Payments}

Salaries, wages, and allowances. The need to pay salaries, wages, and allowances arises from an implicit or formal agreement between the employer and an employee, according to conditions laid down in various acts and regulations. At any point in time, the ministry of finance (and each line ministry) should know, with a fair degree of accuracy, what the salary bill will be into the foreseeable future. Because of the stability, predictability, and regularity of these types of payment, the cash flow is often deemed to occur monthly at the same time as the line ministry's monthly commitment (e.g., from a payroll management system).

Subsistence and travel payments. Commitments usually occur in this category when an approval is signed for travel to be undertaken by an officer. From past records it should be possible to establish when travel normally occurs, when approvals are given, and when the invoices to be paid are received (i.e., how long after the commitment). Past records will show the normal time gaps between each phase — approval/commitment, actual travel, and cash payment.

Other recurrent expenditures. This category contains a variety of items, some where expenditures might be expected to occur simultaneously with the corresponding commitment; others where actual expenditures take place some time after the placing of a requisition or order. However, likely expenditures on most of the items are predictable, including post and telephone services, water, light, and sanitary changes, printing and stationery, etc. The key is to examine each line item and determine the amount and likely pattern of payment.

Grants/transfers. Commitments to pay grants and transfers will be known based on the program developed at the beginning of the year, influenced by law, regulation, and/or policy decisions by the government.

Financing. The profile of debt services and loan receipts and repayments should be readily identifiable from the debt database or corresponding loan agreements.

Furniture, fixtures, and minor capital equipment. Cash payments will normally occur considerably later than the commitment, which will generally occur when a local purchase order or other form of contact is awarded.

Capital projects. This category is probably the most difficult to forecast in terms of both commitments and the associated cash payments. However, most projects are the result of contracts placed, so payment details should (broadly) be known when the contract is signed. The commitment can be for a long period of time (probably more than one year) and expenditure flows tend to be "lumpy." Delays can occur in construction and delivery, so updated forecasts on the progress of work and requirement of funds are regularly needed for these projects. 


\section{Box 2. Payment Arrears-Definition and Reasons}

Arrears can be defined as outstanding payment obligations that the government has failed to discharge in a reasonable period of time. They can arise on any expenditure item, including wages, debt service payments, transfers, and expenditure on goods and services. Arrears may occur for any of a number of different reasons, including:

- Poor budget preparation: Unrealistic budgets overstate revenue and financing so that there is insufficient funding to carry out planned expenditures. Line ministries may thus commit expenditure within budget appropriations, even though there is no cash to discharge all such commitments.

- Poor budget execution: Problems in this area include poor monitoring and control of expenditures which do not adequately constrain government purchases and which allow purchases outside formal procedures to go undetected, and cash allocations that do not match resources approved by the budget.

- Poor budget discipline: Expenditures of certain ministries may be difficult to control by the central ministry of finance (MoF) because of a lack of sanctions against those responsible for breach of compliance with budget regulations.

- Lack of political commitment to agreed financial policies: The authorities may deliberately circumvent the impact on real government spending of financial constraints by recourse to unorthodox sources of financing, notably arrears.

incurrence of arrears in the case of overall revenue shortfalls. Commitment controls based on expenditure ceilings or cash limits reconcile the availability of resources with commitments, thus ensuring that spending units are able to enter into contracts, or other obligations, only if sufficient unencumbered balances are available, or likely to be available at the time of their payments. It is necessary that expenditure ceilings should be guided by a well functioning cash management system.

\section{Preconditions for Successful Implementation of Commitment Controls}

The introduction of effective commitment controls requires a comprehensive approach to strengthening PFM systems. The most important improvements are required in the budget formulation and budget execution processes. A realistic budget is a key precondition for efficient budget execution, including commitment controls. Similarly, commitment controls need to be supported by a good cash planning system for setting credible expenditure ceilings. The essential preconditions for successful implementation of commitment controls are summarized in Box 3 and briefly described below. 


\section{Box 3. Preconditions for Successful Implementation of Commitment Controls}

- Strong political commitment and accountability;

- Sound regulatory framework;

- Realistic budget and adequate budget coverage;

- Effective cash planning and management; and

- Well-established accounting and reporting systems.

Political commitment to the reform process plays a central role. If commitment to the reform process is weak, the chances of success are limited. A major problem for many public sector reforms is that they are introduced in an organization without the willingness to accept the reforms, the technical ability to implement them, or the ability to maintain them once introduced. As a result, the reforms do not succeed or are badly delayed, create distortions that have damaging effects, and, in many cases, are eventually abandoned. Therefore, the decision to introduce expenditure control measures needs to be accompanied by a strong political commitment to the overall reform process that will generate internal support, adequate resources, and an effective change management agenda.

An effective system of control over commitments needs to be supported by a sound regulatory framework, including a Budget System Law (BSL) and financial regulations. In addition to the general legal framework for commitment controls, the BSL should provide clear rules on virements/ reappropriations between the executive and legislature on various broad expenditure categories and distribution of virements powers within the executive-between the ministry of finance (MoF) and line ministries. The executive should have power to withhold budget provision and release of funds in the prescribed conditions. The financial regulations need to set down a detailed system for controlling all types of commitment and preventing accumulation of payment arrears.

The regulatory framework and the PFM procedures should provide enough safeguards so that there can be no deliberate override of controls by any bureaucratic or political authority. When controls are deliberately overridden, opportunities for the diversion of funds into activities not approved by the budget are encouraged. This diversion, by reducing the funds available for legitimate requirements, contributes to arrears. It also encourages spending agencies to view arrears as an option for funding legitimate activities. The regulations need to prescribe a set of sanctions and penalties for noncompliance and financial misconduct in such circumstances.

The credibility of the budget predetermines the quality and the effectiveness of commitment controls. A key indicator for the credibility of the budget is the level of deviation between the approved and the actual budget. In many developing and transition countries, the deviations between approved budgets and actual budget outturns are significant. An analysis of budget allocations compared with real spending (actual payments plus arrears) usually shows that some fixed-cost items, such as utilities, rents, and other unavoidable expenditures (e.g., food for 
prisoners), are often underfunded in the budget. Thus, unrealistic budget projections undermine the process of budget execution, and specifically, the soundness of cash planning, which is the basis for controlling commitments. Therefore, an effective system of commitment controls requires a well-formulated budget with realistic expenditure provisions, guided by sound expenditure policies and priorities.

The lack of a good cash planning and management system, or low quality of cash plans, place practical limitations on the effectiveness of commitment controls. A principal task of commitment controls is to ensure that commitments are only entered when consistent with the budget, and, ideally, with quarterly expenditure ceilings. The principal task of cash planning is to ensure that the quarterly ceilings are consistent with the projected cash availability, which enables them to be used as ceilings for approving commitments. Cash planning on its own will be ineffective unless it is integrated with control over commitments.

Effective commitment controls require a good accounting and reporting system. The ideal situation would be when the accounting and reporting system is organized on an accrual basis, because commitments are formally accounted for in such a system. However, this is not the case in developing countries that apply cash-based recording and reporting. The cash-based systems require additional records with respect to commitments. ${ }^{3}$ In many developing countries, the requirement to control commitments is reflected in the structure of records that should be maintained by budget institutions (typically, in a column in a basic vote book or commitment and expenditure ledger). These ledgers are typically prepared manually and are poorly maintained. At the same time, statutory requirements focus almost exclusively on controlling expenditures with respect to budget appropriations. Accountability to parliament is achieved through annual appropriations that expire at the end of each financial year, and financial reports reflect cash execution of the expenditure plans approved by parliament

A functioning internal and external audit system is also sometimes considered as a precondition for introducing commitment controls. Indeed, an effective system of internal audit is useful for evaluating and improving the effectiveness of internal control processes and management, including the commitment control system. Similarly, external audit can play a useful role in identifying systemic weaknesses in control mechanisms, and suggesting solutions. However, it may be unrealistic to expect that a developing country would have a well functioning internal and external audit system. Almost certainly, the controls will be introduced first and the audit procedures later.

\footnotetext{
3 This paper does not discuss the different recording and reporting bases. For more detail, see International Monetary Fund, Government Finance Statistics Manual 2001.
} 


\section{Institutional Design and Operational Arrangements}

Institutional design and operational arrangements for commitment controls ${ }^{4}$ vary from one country to another. However, the many varieties of commitment control arrangements can be broadly classified in two main categories: centralized and decentralized. Centralized commitment controls are performed by a central agency, usually the MoF or treasury. Decentralized commitment controls are performed by respective line ministries and spending agencies. The most common arrangements for both systems are described below.

\section{Centralized Commitment Controls-MoF/Treasury}

- The line ministry would initially send to the treasury a commitment request on a quarterly basis (broken down according to the budget classification) for continuing commitments (e.g., wages, utilities, scholarships, discretionary allowances, entitlement payments). A commitment request for specific commitments (related to expenditures that require a specific contract or order), would be prepared and sent to the treasury before an order for goods and services is placed, or a commitment is incurred in any form.

- The commitment requests would be examined by the treasury to ensure that the new monetary value does not exceed the uncommitted budget allocation balance and the authorized cash disbursement profile for the line ministry. Once the availability of funds has been verified, the commitment request would be formally approved and recorded by the treasury. No such contract or purchase order would be legally valid until so approved. The treasury would register both the expenditure ceilings/cash disbursement profile and the approved commitment requests.

- Payments would be made only after verification by the treasury that the payment was against an approved commitment. The treasury should discharge the commitment after the payment has been made.

- The treasury information system and the records in the line ministries, as appropriate, should be modified to reflect budget allocations, commitments, cash disbursement profiles, available uncommitted balances, payments, outstanding commitments, and unpaid bills in a distinct manner.

- The treasury should prepare quarterly and monthly in-year budget execution reports that can be directly compared with the budget allocation of expenditures at both the commitment and payment stage.

\footnotetext{
4 There are significant differences in the systems of commitment control between countries from different legal, institutional, and administrative backgrounds, for example between "Anglophone" and "Francophone" systems (though these categories are themselves an oversimplification of reality since there are wide differences of practice between countries from both of these two traditions). These variations in systems and procedures reflect significant differences in the stages and processes of budget execution. The present note focuses primarily on the system of control in countries from the Anglophone tradition.
} 


\section{Decentralized Commitment Controls-Spending Agencies}

- Each ministry should have a commitment control officer (CCO). The head of a ministry/ department should act personally or through an authorized person as a CCO and be responsible for managing commitment controls.

- All expenditure transactions should be processed through the commitment control system.

- The starting point should be for each ministry to prepare a quarterly expenditure plan in a format prescribed by the MoF. This plan, supported by projected monthly cash requirements, should reach the cash management unit in the MoF by a specific day of the month preceding each quarter.

- Based on its annual and three-month rolling cash plan, the MoF would issue quarterly expenditure ceilings broken down by broad categories of expenditure.

- In the event that the quarterly expenditure ceiling is less than the quarterly expenditure plan submitted by a ministry, the plan should be adjusted to match the level of the quarterly expenditure ceiling. The CCO needs to ensure that commitments entered into are consistent with the quarterly expenditure ceiling-without incurring any payment arrears.

- No commitment could be entered into if it exceeds the uncommitted balance available under the relevant budget item and subitem. It is also necessary that the prescribed internal controls—such as administrative and financial authorizations—are complied with.

- Such a strict requirement is practicable for the recurrent budget-but not for capital investment or development projects, where contracts and commitment may extend for six or 12 months. For that reason, a separate six-month expenditure ceiling could be provided for development projects: again CCOs would be required to approve any commitment entered into and satisfy themselves that it is consistent with the prescribed ceilings.

- The authorization of commitments is a particularly important control in such systems. Accordingly, the head of a line ministry should designate only specific officers to authorize the purchase of goods and services, and, to sign and issue a local purchase order. Thus, before any order for goods and services can be placed, or a commitment is otherwise incurred, a clearance needs to be sought from the relevant authorizing officer. A commitment requisition form could be used for initiating a commitment.

\section{Centralized vs. Decentralized System of Commitment Controls}

If the basic PFM systems and control procedures are weak and the organizational arrangements are fragmented, with limited skills and capacity, as in the case of many developing countries, building a centralized system is likely to be the more appropriate and cost-effective way to control expenditure commitments. On the other hand, when basic PFM systems are well established and supported by modern technologies, decentralized commitment controls could be a viable alternative. However, the overall process of decentralizing controls and payment processing requires a number of supporting measures, including: (i) strengthening internal controls, 
accounting, and reporting procedures; (ii) training accountants and establishing local accounting offices within line ministries; (iii) centralizing cash balances; and (iv) developing a sound reporting system with strengthened accountability and transparency.

In practice, the specific arrangements for commitment controls should be guided by the overall organization of the budget execution process, especially with respect to payment and accounting arrangements. A number of countries have moved away from the traditional centralized treasury systems for the execution of the budget as the banking system became more efficient. As a result, the spending agencies were given enhanced powers to control budget implementation, but were held accountable to meet specific performance criteria.

In developing countries, in general, budget execution systems-including internal controls, payment systems, and accounting — need continuous improvement to enhance efficiency and effectiveness in the utilization of resources and delivery of public services. Against this background, current centralized payment systems need to evolve toward involving spending agencies and acquiring more flexibility; and current decentralized systems must better accommodate needs for monitoring, accounting, cash management, and comprehensive audits. However, the centralization of cash balances, central control of the government's bank accounts and a sound reporting system are ideally required in both systems.

\section{Specific Operational Arrangements}

Multiyear commitments ${ }^{5}$ impose additional responsibilities. Such commitments should be incurred only after obtaining the formal approval of the MoF. The spending agencies should be required to submit to the MoF full details of multiyear contracts including the anticipated commitments and payments for each year, which can then be included in the medium-term budget framework. At the annual budget formulation stage, the MoF needs to make full provision for annual commitments and include them in annual and quarterly cash plans. During the budget implementation phase, project managers must keep each project under constant review and report to the budget office and treasury any changes in the appropriations and cash plans.

The level of fixed commitments in budget estimates can play a substantial role for the organization of commitment controls. Although the practices vary from country to country, most PFM systems categorize expenditures in terms of priority. The highest priority expenditures are usually considered fixed commitments that cannot be reduced from their appropriated level. These usually include debt payments and payments of salaries and pensions, but some countries extend the list of priority items to cover poverty-reducing spending and other significant parts of the

\footnotetext{
${ }^{5}$ Multiyear commitments do not include such commitments where a ministry has placed an order in year 1 but receives goods in year 2 . The treatment of outstanding commitments at the end of a year and multiyear commitments should be very much guided by the accounting basis and policies followed by a country.
}

\section{CInternational Monetary Fund. Not for Redistribution}


budget. ${ }^{6}$ The excessive use of fixed commitments usually has a negative impact on the coverage and effectiveness of commitment controls.

A computerized Financial Management Information System (FMIS) can substantially improve the operations of a commitment control system. The FMIS functionality should include a well designed commitment control system. Further, the FMIS needs to require an accurate and timely recording of all commitments and expenditures by the treasury and spending agencies, without which it can not serve as an effective tool of expenditure control. The experience of some countries in this area suggests that arrears continue to be built up even with the introduction of a FMIS, primarily due to agencies' failure to process all commitment transactions through the system.

\section{Implications for IMF Policy and Technical Assistance}

In the context of program and surveillance work and technical assistance, the IMF is especially concerned about fiscal discipline and the accumulation of expenditure arrears in low-income countries. Among other things, the accumulation of arrears is a clear indication of the lack of proper commitment controls. Therefore, the introduction or strengthening of such controls should be considered, in the context of both program and technical assistance work, as a key measure in such circumstances.

Although the introduction of commitment controls is necessary, it is not sufficient to prevent the incurrence or further accumulation of arrears. The development of a commitment control system needs to be supported by concomitant measures in other PFM areas, as described in Section III, particularly with respect to improving the budget formulation process and the overall credibility of the budget, and strengthening cash planning and management.

Technical assistance should especially focus on the design of the commitment control system, and its operational arrangements. The choice of a centralized or decentralized model should be guided by the overall design of the PFM system. As noted, for most developing countries, the centralized model should be the preferable option, because of the generally underdeveloped PFM systems and limited administrative capacity in these countries. However, any concrete recommendations about the institutional design of a commitment control system will require the exercise of judgment, based on the specific country circumstances. When the basic PFM system is well established (a much rarer case in developing countries), the decentralized model of commitment controls could also be applied.

\footnotetext{
${ }^{6}$ The fixed commitments covered over 90 percent of the budget of Georgia in 2003, while arrears increased to 5 percent of GDP.
} 
Regardless of the concrete institutional design of a commitment control system, technical assistance should ensure that it meets the following basic operational requirements:

- A commitment should be incurred only when it is within the budget appropriations and the expenditure ceilings/cash releases approved by the MoF.

- No payment should be made unless it is based on an approved commitment.

- Outstanding commitments and unpaid bills should be monitored on a regular (preferably monthly) basis. ${ }^{7}$

- Payment arrears should not be allowed to accumulate and, if they do, they should be cleared as a matter of priority.

\section{Conclusion}

There are four main lessons emerging from the above discussion:

First, the decision to introduce expenditure control measures, including commitment controls, needs to be accompanied by strong political commitment to the reform process, strengthened credibility of the budget, and the development of an institutional framework that does not allow deliberate override of controls.

Second, the introduction of expenditure controls, including commitment controls, should be regarded as a component of a wider PFM reform process. Reforms that improve cash planning and management, as well as accounting, recording and reporting, are particularly important.

Third, a commitment control system should be properly designed in order to achieve its intended goals. Although the centralized model is a recommended option for developing countries, the decentralized model could also be applied in certain circumstances, particularly when the basic PFM system is well established.

Fourth, the introduction or strengthening of commitment controls, as a component of a broad PFM reform process, is key to addressing the problem of expenditure arrears, in the context of the IMF's operational work and technical assistance.

\footnotetext{
7 A distinction needs to be made between "outstanding commitments" and "unpaid bills." Unpaid bills are those where goods and services have been provided, and bills are overdue for payment. A proper accounting system using the concept of accounts payable would clearly reflect the extent of outstanding unpaid bills. Alternately, it is necessary to separate arrears from outstanding commitments.
}

\section{CInternational Monetary Fund. Not for Redistribution}




\section{References}

Allen, R., and D. Tommasi, 2001, Managing Public Expenditure: A Reference Book for Transition Countries (Paris: Organization for Economic Cooperation and Development).

Diamond, J., and P. Khemani, 2005, Technical Assistance Evaluation-Public Expenditure Management Reform in Anglophone Countries (Washington: International Monetary Fund).

Potter, B., and J. Diamond, 1999, Guidelines for Public Expenditure Management (Washington: International Monetary Fund). 